\title{
Pembuatan Alat Pendeteksi Kadar Logam Pada Air Berbasis Aduino UNO
}

\author{
Dany Pratmanto ${ }^{[1]}$, Angga Ardiansyah ${ }^{[2]}$, Andrian Eko Widodo ${ }^{[3]}$, Fakihotun Titiani ${ }^{[4]}$ \\ STMIK Nusa Mandiri Jakarta ${ }^{[1,2,3]}$, Univeristas Bina Sarana Informatika ${ }^{[4]}$ \\ e-mail: dany.dto@nusamandiri.ac.id, angga.axr@nusamandiri.ac.id, andrian.aeo@nusamandiri.ac.id \\ fakihtiani@gmail.com
}

\begin{abstract}
In the current era of globalization, information technology is accelerating. The computer is an equipment created to facilitate human work, when achieving progress both in the manufacture of hardware and software. There are so many factories that are built in big cities and small towns and some are even in the middle of residential areas. Factory waste can cause a polluted environment including pollution in water that causes disease. For this reason, the author is trying to make the final project about the production of metal laying detectors on Arduino-Based Water UNO. This detector can detect metal levels in water, conductivity sensors will detect water and determine whether or not the water is based on the Regulation of the Minister of Health of the Republic of Indonesia number 492 of 2010 concerning the requirements of drinking water quality. This tool can make it easier for people to find out whether or not water is feasible in the environment.
\end{abstract}

Keywords-Detectors, Metal Detectors on Water

Abstrak - Dalam era globalisasi sekarang ini, teknologi informasi melaju dengan cepatnya. Adapun computer yang merupakan peralatan yang diciptakan untuk mempermudah pekerjaan manusia, saat mencapai kemajuan baik di dalam pembuatan hardware maupun software. Banyak sekali pabrik yang dibangun di kota besar maupun kota kecil bahkan ada yang di tengah-tengah pemukiman warga. Limbah pabrik dapat menyebabkan lingkungan tercemar termasuk pencemaran pada air yang menimbulkan adanya penyakit. Alat pendeteksi ini dapat mendeteksi kadar logam pada air, sensor konduktivitas akan mendeteksi air dan dan menentukan layak atau tidaknya air tersebut berdasarkan Peraturan Menteri Kesehatan Republik Indonesia nomor 492 tahun 2010 tentang persyaratan kualitas air minum. Alat ini dapat mempermudah masyarakat untuk mengetahui dengan mudah layak atau tidaknya air pada lingkungan tersebut.

Kata kunci — Alat Pendeteksi, Pendeteksi Logam pada Air

\section{A. PENDAHULUAN}

Menurut Sidik perkembangan teknologi dan kebutuhan manusia yang meningkat merupakan dua hal yang saling mempengaruhi satu sama lain. Kebutuhan manusia yang meningkat akan memicu perkembangan teknologi, sedangkan perkembangan teknologi juga akan memacu kebutuhan lain untuk menangani dampak negatif dari adanya teknologi baru. Dalam dunia modern, tentunya banyak sekali teknologi yang berkembang (Setiawan, 2017).

Sebagian besar masyarakat Indonesia masih mengkonsumsi air sumur, air telaga ataupun air sungai. Untuk memastikan kualitas air yang pantas konsumsi, dibutuhkan adanya upaya pengolahan yang baik serta pengawasan secara rutin. Oleh sebab itu, proses uji kelayakan air guna dikonsumsi sangat diperlukan oleh lembaga penguji maupun masyarakat. Saat ini, umumnya dilaksanakan pengujian kelayakan air di laboratorium (Juliastuti, Fauzy, \& Widodo, 2017). Pada proses tersebut pemungutan sampel dilaksanakan di tempat uji, lantas proses pengukuran dilaksanakan di laboratorium. Proses ini membutuhkan waktu serta ongkos yang relatif mahal. Berdasarkan keterangan dari Peraturan Menteri Kesehatan Republik Indonesia nomor 492 tahun 2010, air pantas digunakan ialah air yang melewati proses pengolahan atau tanpa proses pengolahan yang mengisi syarat kesehatan dan bisa langsung diminum. Kadar maksimum yang diperbolehkan yaitu (Besi $=0,3 \mathrm{mg} / \mathrm{l}$, TDS $=500$ $\mathrm{mg} / \mathrm{l}$, Aluminium=0,2 $\mathrm{mg} / \mathrm{l}$, Mangan=250 $\mathrm{mg} / \mathrm{l}$, Seng $=3 \mathrm{mg} / \mathrm{l}$, Sulfat $=250 \mathrm{mg} / \mathrm{l}$, Tembaga $=2$ $m g \Lambda$, Nikel=0,07 $\mathrm{mg} / \mathrm{l}$, Timbal=0,01 $\mathrm{mg} / \mathrm{l})$. Berdasarkan data tersebut penulis akan menitik beratkan pada parameter besi $(F e)$ karena banyak air yang tercemar dengan kadar besi yang tinggi seperti sungai pada daerah perindustrian yang tercemar limbah pabrik dan sangat tidak baik bagi kesehatan.

Menurut Parulian "Logam Fe adalahlogam essensial yang keberadaannya dalam jumlah tertentu sangat diperlukan oleh organisme hidup, tetapi dalam jumlah berlebih dapat memunculkan efek racun. Tingginya kandungan logam Fe akan dominan terhadap 
kesehatan insan diantaranya dapat menyebabkan keracunan (muntah), kehancuran usus, penuaan dini sampai kematian mendadak, radang sendi, cacat lahir, gusi berdarah, kanker, sirosis ginjal, sembelit, diabetes, diare, pusing, gampang lelah, hepatitis, hipertensi, insomnia" (Supriyantini, 2015).

\section{B. TINJAUAN PUSTAKA}

\section{Arduino UNO}

Menurut menyimpulkan bahwa:

(Arduino,

2018)

Arduino UNO adalah papan mikrokontroler yang berbasis ATMega328P. Arduino jenis ini memiliki 14 pin input maupun output digital, 6 input analog, Kristal kuarsa 16 Mhz, koneksi USB, power jack, header ICSP dan tombol reset. Semua pin-pin ini yang dibutuhkan untuk menjalankan mikrokontroler. Cukup dengan menghubungkan computer dengan kabel USB ataupun hubungkan dengan adapter. $A C$ dan $D C$ ataupun baterai untuk memulai.

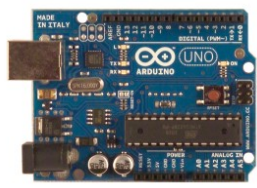

Sumber:https://store.arduino.cc/usa/arduinouno-rev3

\section{Gambar II.1. board Arduino UNO}

\section{Sensor}

Menurut (Suleman, 2014)"Sensor merupakan transduser yang berfungsi untuk mengolah variasi gerak, panas, cahaya atau sinar, magnetis, dan kimia menjadi tegangan serta arus listrik".

Sensor Konduktivitas memiliki desain yang kompak. Probe sensornya berbahan stik stainles yang berfungsi sebagai penerima data dari bahan yang diuji. Sensor ini bisa langsung disambungkan dengan pin analog Arduino maupun pin analog mikrokontroller lainnya, tanpa mesti menggunakan modul penguat tambahan.

Sensor Konduktivitas memiliki desain yang kompak. Probe sensornya berbahan stik stainles yang berfungsi sebagai penerima data dari bahan yang diuji. Sensor ini bisa langsung disambungkan dengan pin analog Arduino maupun pin analog mikrokontroller lainnya, tanpa mesti menggunakan modul penguat tambahan.

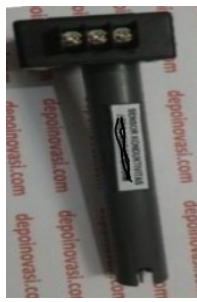

Sumber: Penulis

Gambar II.2. Sensor Konduktivitas

\section{Buzzer}

Menurut (Fadlilah et al., 2018) "Buzzer adalah suatu komponen elektronika yang bermanfaat untuk mengolah getaran listrik menjadi getaran suara". Buzzer nyaris sma dengan loud speaker, jadi buzzer pun terdiri dari kumparan yang terpasang pada diafragma dan lantas kumparan itu dialiri arus sampai-sampai menjadi elektromagnet. Kumparan tadi bakal tertarik ke dalam atau keluar, tegantung dari arah arus dan polaritas magnetnya sebab kumparan dipasang pada diafragma maka masing-masing gerakan kumparan bakal menggerakkan diafragma secara bolak-balik sehingga menciptakan udara bergetar yang bakal menghasilkan suara. Buzzer bisa digunakan sebagai indikator bahwa proses telah selesai atau terjadi suatu kesalahan pada sebuah alat (alarm).

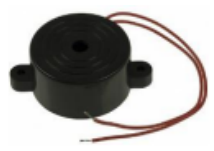

Sumber: (St \& Fahruzi, 2016)

Gambar II.3. Buzzer

\section{LCD (Liquid Cristal Display)}

Menurut (Suleman, 2014) "LCD (Liquid Cristal Display) adalah suatu display dari bahan cairan kristal yang pengoperasiannya menggunakan sistem dot matrix". Kegunaan LCD tidak sedikit sekali dalam perancangan sebuah sistem dengan memakai mikrokontroler, LCD dapat bermanfaat untuk memperlihatkan suatu nilai hasil sensor, memperlihatkan teks, atau memperlihatkan menu pada software mikrokontroler. LCD matrix $16 \times 2$ sebagai 
output tampilannya. Modul LCD matrix terdapat dengan konfigurasi 16 karakter dan 2 baris dengan masing-masing karakternya disusun oleh baris pixel. Fitur yang disajikan dalam LCD ini diantaranya terdiri dari 16 karakter dan 2 baris, memiliki 192 karakter, ada karakter generator terprogram, bisa dialamati dengan mode 4 bit dan 8 bit dan pun dilengkapi dengan back light. (Dinata \& Sunanda, 2015)kondisi/keadaan tersebut. Pada biasanya statechart diagram mencerminkan* class tertentu (satu class bisa* memliki lebih dari satu statechart diagram).

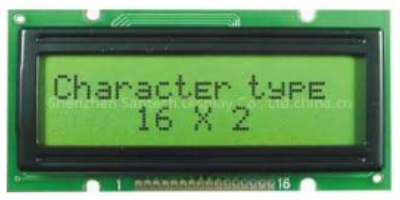

Sumber: (Mikro, Keausan, Rem, \& Api, 2014)

Gambar II. 4. LCD

\section{Bahasa Pemrograman}

Menurut (Fadlilah et al., 2018) "Bahasa pemrograman ialah notasi yang dipakai untuk mencatat program (komputer)".

Arduino menggunakan sebuah kode program khusus yang mirip dengan struktur bahasa $\mathrm{C}$.

\section{Arduino IDE}

Menurut (Fadlilah et al., 2018) Untuk memprogram board Arduino, anda butuh software IDE (Integrated Development Environment) bawaan dari Arduino. Aplikasi ini bermanfaat untuk membuat, membuka, dan mengedit source code. Dalam Arduino menggunakan bahasa pemrograman $\mathrm{C++}$. Bahasa pemrograman ialah notasi yang dipakai untuk mencatat program (komputer). Bahasa ini dipecah menjadi 3 tingkatan yakni bahasa mesin, bahasa tingkat rendah dan bahasa tingkat tinggi. Bahasa mesin (machine language) berupa micro instruction atau hardwire. Programnya paling panjang dan susah dipahami.

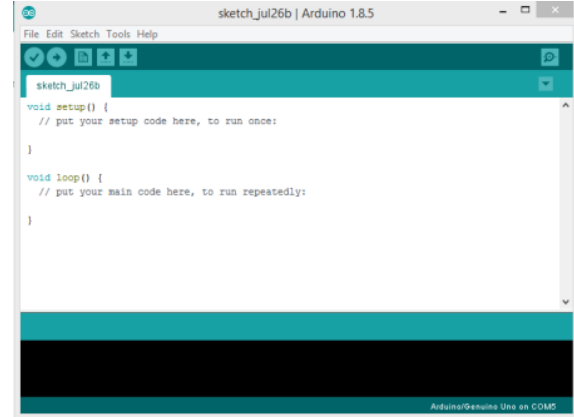

Sumber: Penulis

Gambar II.5. Tampilan Arduino IDE

\section{METODE PENELITIAN}

Metode penelitian yang digunakan dalam pembuatan alat ini adalah analisis kualitatif, beberapa metode dalam pengumpulan data, yaitu:

1. Observasi

Penulis melakukan pengamatan langsung terhadap obyek yang telah diambil dan membuat pendeteksi kadar logam pada air berbasis Arduino UNO.

2. Studi Pustaka

Penulis mempelajari buku-buku referensi, jurnal, browsing di internet dan literaturliteratur lain.

3. Wawancara

Penulis melakukan wawancara yang berkaitan dengan alat yang penulis buat dengan orang yang lebih mengetahui tentang elektro.

\section{HASIL DAN PEMBAHASAN}

\section{Tinjauan Umum Alat}

Alat pendeteksi kadar logam pada air ini merupakan elektronika berbasis Arduino UNO dan menggunakan sensor konduktivitas. Alat ini digunakan untuk mengetahui berapa kadar logam yang terkadung pada air, apakah kadar logam yang terkandung pada air termasuk kategori layak atau tidak layak digunakan.

\section{Blok Rangkaian Alat}

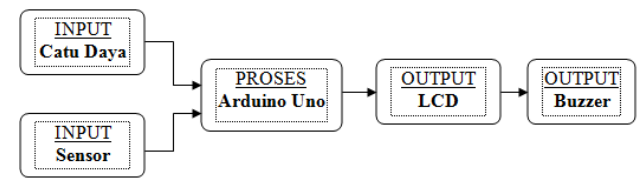

Gambar III.1. Blok Diagram Alat 
Penjelasan blok diagram alat sebagai berikut:

\section{a. Input}

Komponen input ini merupakan masukan yang akan diproses. Komponen input ini terdiri dari:

1) Catu Daya merupakan masukan tegangan +12 volt kedalam rangkaian.

2) Sensor Konduktivitas berfungsi untuk mendeteksi kadar logam pada air.

b. Proses

Proses merupakan komponen utama yang berfungsi sebagai pengelola data yang diterima dari masukan yang kemudian akan menghasilkan output. Dalam proses ini penulis menggunakan Arduino UNO R3.

\section{c. Output}

Output merupakan keluaran dari semua proses yang telah dijalankan. Output yang dihasilkan yaitu:

1) Buzzer berfungsi sebagai indikasi hasil input yang menghasilkan bunyi beep seperti alarm.

2) $L C D$ berfungsi sebagai indikator hasil input untuk menampilkan kondisi air yang telah terdeteksi.

\section{Skema Rangkaian ALat}

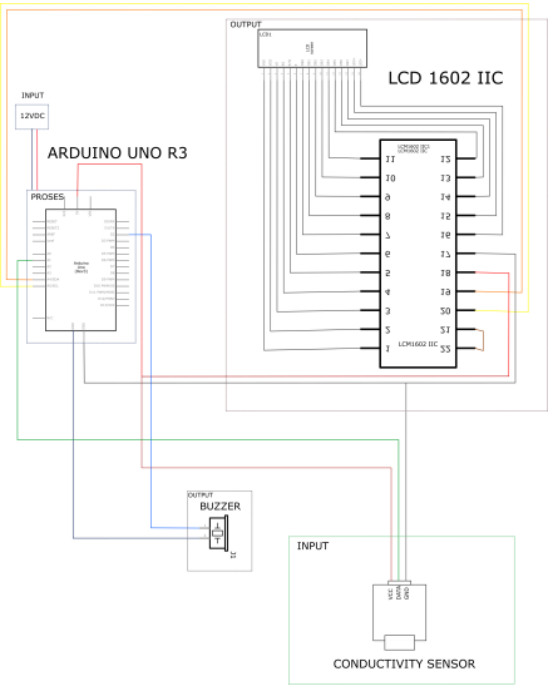

Gambar III. 2. Skema Rangkaian Alat
Rangkaian ini adalah skema pembuatan alat pendeteksi kadar logam pada air yang menggunakan Arduino Uno sebagai proses data, dengan menggunakan catu daya adaptor sebesar 12 volt $A C$ dan rangkaian elektronika lain sebagai pendukung alat.

Untuk menjalankan alat ini, hubungkan alat dengan catu daya 12 volt $A C$, kemudian masukan sensor ke dalam obejct yang akan dideteksi. Kemudian jika air yang telah terdeteksi kadar logamnya kurang dari 0,3 mg/l status pada LCD air tersebut dikatakan "Layak"dan buzzer tidak berbunyi, jika kadar logam lebih dari 0,3 mg/l maka air tersebut dikatakan "Tidak Layak" kemudian buzzer akan mengeluarkan berupa suara beep.

\section{Flowchart}

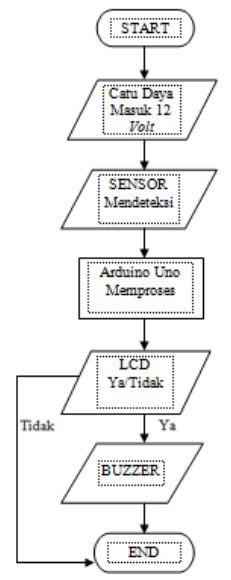

Gambar III. 3. Flowchart Program

\section{Hasil Percobaan Keseluruhan}

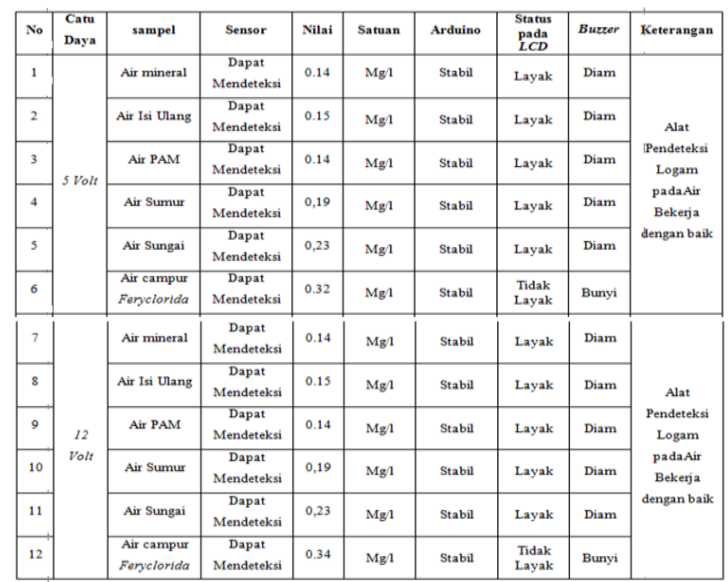




\section{E. KESIMPULAN}

Dalam pembuatan alat ini yang berjudul "Pembuatan Alat Pendeteksi Kadar Logam pada Air Berbasis Arduino UNO" penulis dapat menyimpulkan sebagai berikut:

1. Hasil rancangan alat ini dibuat menggunakan beberapa komponen yaitu menggunakan sensor konduktivitas untuk mendeteksi object, Arduino UNO sebagai proses pengolahan data, $L C D$ dan buzzer sebagai output, catu daya 12 volt.

2. Sensor konduktivitas bekerja dengan baik ditandai dengan adanya inputan kadar logam yang dihasilkan oleh sensor berupa angka.

3. Alat ini dapat mendeteksi kadar logam pada air dengan kondisi jika kadar logam pada air yang terdeteksi kurang dari 0.3 mg/l maka status layak, jika kadar logam lebih dari $0.3 \mathrm{mg} / \mathrm{l}$ maka statusnya tidak layak.

\section{DAFTAR PUSTAKA}

[1] Andrianto H \& Darmawan A. (2017). Arduino belajar cepat dan pemrograman. Bandung: Informatika.

[2] Arduino. (2018). Arduino product. Retrieved from https://arduino.cc

[3] Efrianto, E., Ridwan, R., \& Fahruzi, I. (2016). Sistem pengaman motor menggunakan smartcard politeknik negeri batam. Integrasi, 8(1), 1-5.

[4] Fadlilah, N. I., Arifudin, A., \& Informatika, T. (2018). Pembuatan Alat Pendeteksi Gempa Menggunakan. Evolusi, 6(1), 6167. Retrieved from https://ejournal.bsi.ac.id/ejurnal/index.php levolusi/article/download/3582/2280

[5] Haidir, A., Salim, A., Studi, P., Komputer, T., Labu, P., Selatan, J., ... Selatan, J. (n.d.). PEMBUATAN ALAT ARGO UNTUK TRANSPORTASI UMUM OJEK MOTOR DENGAN SENSOR PHOTODIODA.

[6] Jatmika. (2011). Cara Mudah Merakit Robot. Jakarta Selatan: FlashBokk.

[7] Juliastuti, E., Fauzy, L. I., \& Widodo, R. T. (2017). Alat Ukur Portabel Kadar Logam Mangan dan Besi dalam Air Menggunakan Prinsip Spektrofotometer, 9(2), 71-80.
[8] Kadir, A. (2012). Algoritma \& Pemrograman Menggunakan Java. Yogyakarta: Andi Offset.

[9] Maulana, Y. I., Studi, P., \& Informatika, M. (2017). PERANCANGAN PERANGKAT LUNAK SISTEM INFORMASI PENDATAAN GURU DAN SEKOLAH ( SINDARU ) PADA, 13(1), 21-27.

[10]Mikro, S., Keausan, D. A. N., Rem, B., \& Api, K. (2014). Jurnal INFOTEKMESIN Volume 7 Edisi Januari 2014 Jurnal INFOTEKMESIN Volume 7 Edisi Januari 2014, 7(1), 78-87.

[11]Pitowarna. (2008). Desain Control, dan kecerdasan buatan. Yogyakarta: Andi Offset.

[12] Setiawan, S. (2017). Aplikasi Pengaman Kendaraan Berbasis Mikrokontroler Atmega 8 Dan Attiny 2313. Jurnal Techno Nusa Mandiri, 14(1), 21-26. Retrieved from http://ejournal.nusamandiri.ac.id/ejurnal/in dex.php/techno/article/view/390

[13] St, S., \& Fahruzi, I. (2016). Sistem Pengaman Motor Menggunakan Smartcard Politeknik Negeri Batam Electrical Engineering study Program, 8(1), 1-5.

[14] Steven Jendri Sokop, Dringhuzen J. Mamahit, S. R. U. . S. (2016). Trainer Periferal Antarmuka Berbasis Mikrokontroler Arduino Uno. E-Journal Teknik Elektro Dan Komputer vol.5 no.3 (2 016), ISSN : 2301-8402, 5(3), 13-23.

[15] Suleman, S. (2014). Rancangan Prototype Alat Pengukur Tinggi Muka Air. Rancangan Prototyfe Alat Pengukur Tinggi Muka Air Pada Bendungan, (2), 83-90.

[16] Suprayogi, D. (2018). Rancang Bangun Sistem Monitoring Dan Penyiraman Menggunakan Arduino Uno, 613-618. Retrieved from https://jurnal.teknikunkris.ac.id/index.php/ SEMNASTEK/article/view/98/93

[17] Supriyantini, E. (2015). Kandungan Logam Berat Besi ( Fe ) Pada Air , Sedimen, Dan Kerang Hijau ( Perna viridis ) Di Perairan Tanjung Emas Semarang, 18(1), 38-45. 
[18]Winarno \& Deni Arifianto. (2011). Bikin Robot itu Gampang (Pertama). Surabaya: PT Kawan Pustaka. 